\title{
The Optimization of Fracturing Parameters of Horizontal Well under Different Reservoir Conditions in Tight Sandstone Gas Reservoir
}

\author{
Hua Wen \\ Key Laboratory of Enhanced Oil and Gas Recovery in \\ Ministry of Education, \\ Northeast Petroleum
}

\author{
Na Sun \\ University, Daqing, 163318, China Gas Recovery Plant, \\ Jinlin Oil Field, CNPC, \\ Songyuan, 138000, China
}

\begin{abstract}
In order to ensure the good fracturing effect of horizontal well in the Sulige gas field, block SuX of Sulige gas field was used as an example, the typical horizontal wells of different fracturing mode were selected. According to the different reservoir conditions, the fracturing mode of horizontal well was optimized, the hybrid PEBI meshing method of near wellbore module (NWM) of numerical simulation software named Eclipse was used to mesh the typical horizontal well area, the coupling relationship between the fracture of fractured horizontal well and wellbore and matrix was described, the coupled numerical simulation model between the matrix of gas reservoir and fracture was established, the fracture parameters including fracture interval, fracture half length and fracture conductivity of different fracturing mode of horizontal wells were reasonably optimized using numerical simulation method, the reasonable configuration relationship between the reservoir conditions and the fracturing parameters of horizontal well were established. The results indicate that, the different fracturing mode is suitable for the reservoir conditions, and the reasonable fracturing parameter is suitable for the fracturing mode.
\end{abstract}

Keywords-tight sandstone gas reservoir; reservoir conditions; PEBI grid; fracturing parameter; horizontal well; numerical simulation

\section{INTRODUCTION}

In recent years, the application scale of horizontal well fracturing became more and more wide, and has become an effective mean to change development mode and improve the recovery ratio of Sulige gas field. Differences between the development effect of fractured horizontal well were larger, the initial production of some horizontal wells were high, the initial production of some horizontal wells were low, the production of some horizontal wells declined rapidly, and the period of stabilized production of some horizontal wells were longer [1]. The candidate well and layers should have certain reservoir conditions, and match fracturing parameters, so as to ensure fractured horizontal well to achieve good results. The optimization of reservoir conditions of fractured horizontal well and the optimization of fracturing parameters under the multi factors have become one of the urgent problems to be solved, and it was technique bottleneck that restricted the application of horizontal wells in the Sulige gas field [2-3]. Therefore, block SuX was used as an example, the fracturing mode of horizontal well suited for different reservoir conditions was optimized using the mathematical statistics analysis method, and the typical horizontal wells of different fracturing mode were selected, the coupled numerical simulation model between the matrix of gas reservoir and fracture was established using the near wellbore module (NWM) of numerical simulation software named Eclipse [4-7], the reasonable fracturing parameters of different fracturing mode were optimized using the numerical simulation method. The study results can better guide the optimization design of horizontal well fracturing; there is important practical significance for improving the effect and success rate of horizontal well fracturing.

\section{THE CONFIGURATION RELATIONSHIP BETWEEN RESERVOIR CONDITIONS AND FRACTURING MODE}

In the SuX gas field, 23 wells were selected, including segment multi-fracture volume fractured horizontal wells, large-scale fractured horizontal wells, long horizontal segment fractured horizontal wells, conventional fractured horizontal wells. The reservoir conditions of horizontal wells of different fracturing mode were counted and evaluated, the appropriate fracturing mode were determined under the different reservoir conditions. Table I shows that, the segment multi-fracture volume fracturing mode (SMVFM) is suitable for the reservoir conditions that the gas bearing net pay is $2 \sim 9 \mathrm{~m}$, net pay length of horizontal segment is $650 \sim 900 \mathrm{~m}$, cumulative interlayer thickness is $0 \sim 1.5 \mathrm{~m}$; the large-scale fracturing mode (LSFM) is suitable for the reservoir conditions that the gas bearing net pay is $4 \sim 6 \mathrm{~m}$, net pay length of horizontal segment is less than $500 \mathrm{~m}$, cumulative interlayer thickness is $0 \sim 1 \mathrm{~m}$; the long horizontal segment fracturing mode (LHSFM) is suitable for the reservoir conditions that the gas bearing net pay is $1 \sim 3 \mathrm{~m}$, net pay length of horizontal segment is more than $900 \mathrm{~m}$, cumulative interlayer thickness is $0 \sim 1.5 \mathrm{~m}$; the conventional fracturing mode (CFM) is suitable for the reservoir conditions that the gas bearing net pay is $1 \sim 8 \mathrm{~m}$, net pay length of horizontal segment is less than $650 \mathrm{~m}$, cumulative interlayer thickness is $0 \sim 2.5 \mathrm{~m}$.

Through the analysis of statistics law, the SMVFM is suitable for the reservoir conditions that gas pay is larger, net pay length of horizontal segment is larger, and cumulative interlayer thickness is smaller; the LSFM is suitable for the reservoir conditions that gas pay is moderate and continuous, net pay length of horizontal segment is 
smaller, and cumulative interlayer thickness is smaller; the LHSFM is suitable for the reservoir conditions that gas pay is thinner and more continuous, cumulative interlayer thickness is smaller; the CFM is suitable for the reservoir conditions that cumulative interlayer thickness is larger.

TABLE I. The configuration relationship table between the reservoir conditions of horizontal well and fracturing mode

\begin{tabular}{cccc}
\hline & \multicolumn{2}{c}{ Reservoir conditions } \\
\cline { 2 - 4 } Fracturing mode & $\begin{array}{c}\text { Gas bearing } \\
\text { net pay } \\
{[\mathrm{m}]}\end{array}$ & $\begin{array}{c}\text { Net pay length of horizontal segment } \\
{[\mathrm{m}]}\end{array}$ & $\begin{array}{c}\text { Cumulative interlayer thickness } \\
\text { SMVFM }\end{array}$ \\
\hline LSFM & $2 \sim 9$ & $650 \sim 900$ & $0 \sim 1.5$ \\
\hline LHSFM & $4 \sim 6$ & $>500$ & $0 \sim 1$ \\
\hline CFM & $1 \sim 3$ & $<600$ & $0 \sim 1.5$ \\
\hline
\end{tabular}

III. THE COUPLED MODEL BETWEEN THE MATRIX OF GAS RESERVOIR AND FRACTURE

\section{A. Meshing method}

The hybrid PEBI meshing method of near wellbore module (NWM) of numerical simulation software named Eclipse was used to simulate hydraulic fracture of fractured horizontal well. The hybrid PEBI grid are characterized by high computation efficiency, good stability, flexibility and other characteristics, its advantages can describe the complicated hydraulic fracture; actually and reliably describe the coupling relationship between the hydraulic fracture of horizontal well fracturing and the wellbore and the matrix. The hybrid PEBI grid brings many conveniences for the establishment of the hybrid grid and local grid refinement, and it will become the dominant grid of future gas reservoir numerical simulation [4-6]. Meshing method of horizontal well fracturing: the hybrid PEBI hexagonal or rectangular grid was used for the matrix region outside the wellbore, the radial grid was used for the vertical wellbore region, the parallel rectangular grid was used for the horizontal wellbore region, the NWM of Eclipse was used to design the main hydraulic fracture with fracture parameters including fracture length, fracture conductivity, fracture width, and so on; the method that grid conductivity or permeability were modified was used for the communication volume of secondary fracture around the main fracture.

B. The coupled model between the matrix of gas reservoir and hydraulic fracture

The work flow and work principle of the NWM module in Eclipse: first, the volume of interest (VOI) was divided from the full field model (FFM); the well trajectories within the VOI were updated using the related well data. Then the boundary exchange conditions between the VOI region and FFM region were defined, the regular or irregular grid were generated within the VOI region according to the requirement using the hybrid PEBI meshing technique. Grid property values were re-interpolated through the original gas reservoir model. Thus far, the near wellbore module had been established, can be carried out independently, can also be put into the FFM for calculation [7]. The VOI was the coupled model between the matrix of gas reservoir and hydraulic fracture, which can reflect the filtration mechanism of matrix and hydraulic fracture.

\section{THE OPTIMIZATION OF FRACTURING PARAMETERS OF HORIZONTAL WELL}

\section{A. Basic parameters}

The typical horizontal wells of different fracturing mode were selected, including SuX-27H, SuX-62H, SuX-48H and SuX-49H, who's the coupled numerical simulation model between the matrix of gas reservoir and hydraulic fracture was respectively established. The basic parameters of hydraulic fracture were shown in Table II, the proration productions of typical horizontal wells were $6 \times 10^{4} \mathrm{~m}^{3} / \mathrm{d}$, the abandoned bottom hole pressures were $2 \mathrm{MPa}$, the abandoned gas production rates were $0.14 \times 10^{4} \mathrm{~m}^{3} / \mathrm{d}$. Based on the coupled numerical simulation model, according to the purpose of the study, when fracture interval, fracture half length, fracture conductivity was respectively changed, while the other basic parameter was unchanged, the numerical simulation method was used to simulate the change laws of production time and gas production rate of horizontal well, and the reasonable fracturing parameters were optimized. 
TABLE II. The basic parameters of hydraulic fracture

\begin{tabular}{ccccc}
\hline Fracturing mode & $\begin{array}{c}\text { Typical } \\
\text { horizontal } \\
\text { well }\end{array}$ & $\begin{array}{c}\text { Fracture } \\
\text { interval } \\
{[\mathrm{m}]}\end{array}$ & $\begin{array}{c}\text { Fracture half length } \\
{[\mathrm{m}]}\end{array}$ & $\begin{array}{c}\text { Fracture } \\
\text { conductivity } \\
{\left[\mu \mathrm{m}^{2} . \mathrm{cm}\right]}\end{array}$ \\
\hline SMVFM & SuX-27H & 60 & 60 & $\begin{array}{c}\text { Number of } \\
\text { fracture } \\
{[\mathrm{n}]}\end{array}$ \\
\hline LSFM & SuX-62H & 130 & 100 & 15 \\
\hline LHSFM & SuX-48H & 110 & 100 & 80 \\
\hline CFM & SuX-49H & 130 & 100 & 80 \\
\hline
\end{tabular}

\section{B. Fracture interval}

When the number of fracture, fracture half length and other fracture parameters were unchanged, while that the different fracture interval influences the deliverability of fractured horizontal well was researched. The numerical simulation results are shown in Fig.1 and Fig.2, which indicate that, the fracture interval extremely influence the well-controlled dynamic reserve, the total gas production and the recovery ratio of horizontal well, with the increase of fracture interval, the period of stabilized production and total gas production increase, the increasing trend become slow, a fracture interval limit exists, when it is more than the fracture interval limit, the period of stabilized production and the total gas production turn obviously and flatten out. The main reasons are that, when the fracture interval is small, the gas drainage radius of adjacent fractures overlap, there are some certain interferences between the adjacent fractures during the production process, which make the production of horizontal well become lower; with the increase of fracture interval, and the distance between two fractures continuously approaches the

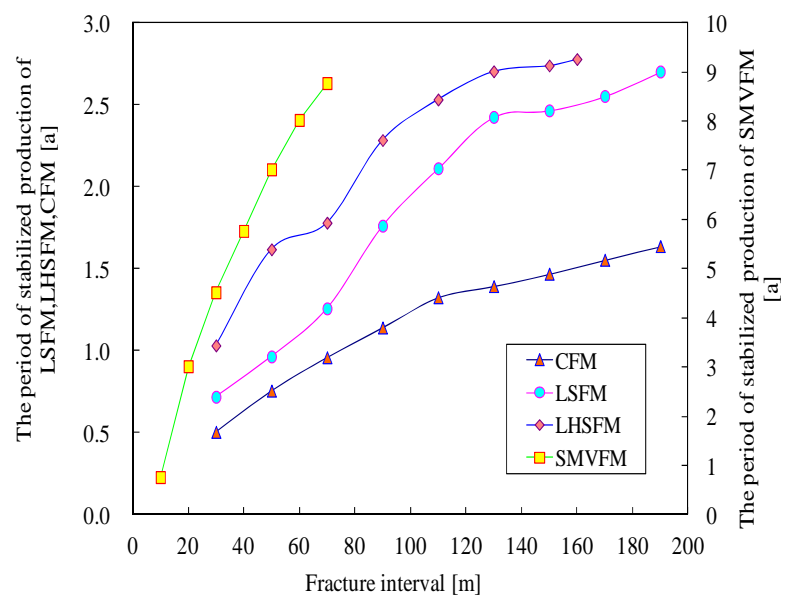

Figure 1. The relationship curve between the period of stabilized production and fracture interval of different fracturing mode.

\section{Fracture length}

That the different fracture half length influences the deliverability of fractured horizontal well was researched. The simulation results are shown in Fig.3 and Fig.4, which indicate that, when the number of fracture and the fracture interval are unchanged, while with the increase of fracture half length, the period of stabilized production and the total sum of gas drainage radius of two adjacent fractures, the location allocation of fracture tends to be reasonable, the deliverability of horizontal well increases gradually, and the deliverability reaches the maximum at the optimal fracture interval; with the continual increase of fracture interval, and the distance between two fractures is gradually more than the sum of gas drainage radius of two adjacent fractures, the deliverability of horizontal well tends to be almost constant, and changes a little; if the fracture interval is too large, it is bound to cause the loss of reserves between fractures. Therefore, the reasonable fracture interval can ensure the horizontal well with high well-controlled dynamic reserve, and can ensure the horizontal well with high deliverability and recovery. The reasonable fracture interval range of segment multi-fracture volume fracturing is $40 \sim 60 \mathrm{~m}$, the reasonable fracture interval range of large-scale fracturing is $90 \sim 130 \mathrm{~m}$, the reasonable fracture interval range of long horizontal segment fracturing is $90 \sim 110 \mathrm{~m}$, the reasonable fracture interval range of conventional fracturing is 90 130m.

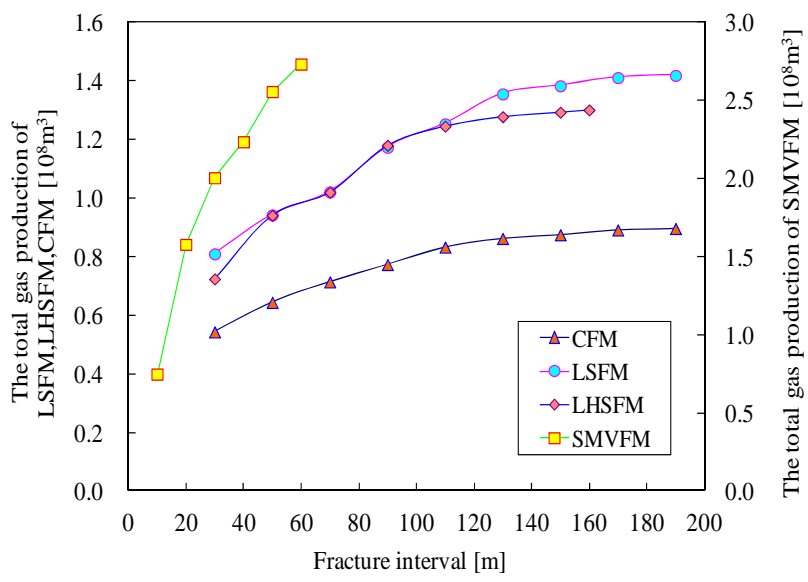

Figure 2. The relationship curve between the total gas production and fracture interval of different fracturing mode.

gas production increase, but the increasing trend become extremely slow, a fracture half length limit exists, when it is more than the fracture half length limit, the period of stabilized production and the total gas production of the fractured horizontal well turn obviously and flatten out. Because the fracture half length grows longer, the flow resistance of gas from the fracture flows into the wellbore is larger, so that the flux of gas in the fracture and formation 
flows into the wellbore relatively decreases, so the increase amplitude of gas production rate of horizontal well decreases. Therefore, the reasonable fracture half length range of segment multi-fracture volume fracturing is $40 \sim 60 \mathrm{~m}$, the reasonable fracture half length range of largescale fracturing is $100 \sim 120 \mathrm{~m}$, the reasonable fracture half

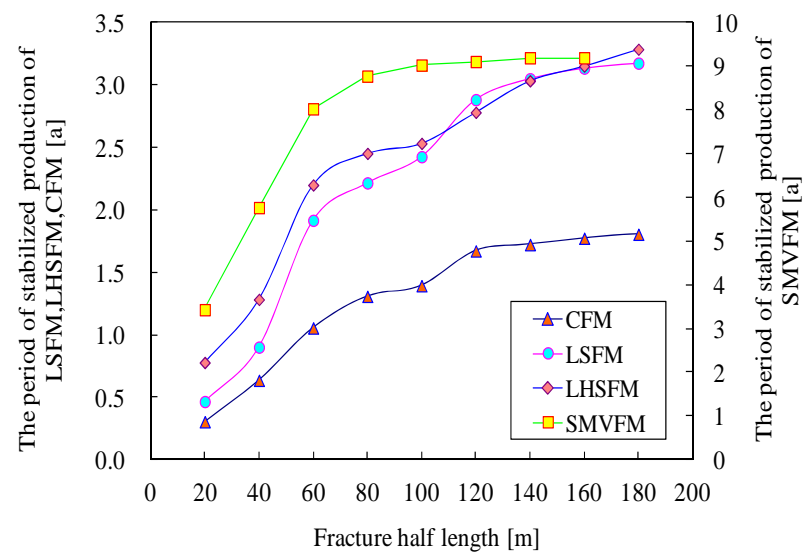

Figure 3. The relationship curve between the period of stabilized production and fracture half length of different fracturing mode.

\section{Fracture conductivity}

The fracture conductivity is the product of fracture width and permeability, with the development of fracturing technique, the fracture conductivity that fracturing technology can provide is more and more big. The practices show that, the effect of fracture conductivity on the deliverability of fractured horizontal well is larger. The simulation results that the fracture conductivity influences the deliverability of horizontal well are shown in Fig.5 and Fig.6, which indicate that, when the other fracture parameters are unchanged, while with the increase of fracture conductivity, the period of stabilized production and the total gas production increase, the trend become slow, a fracture conductivity limit exists, when it is more than the fracture conductivity limit, the period of stabilized

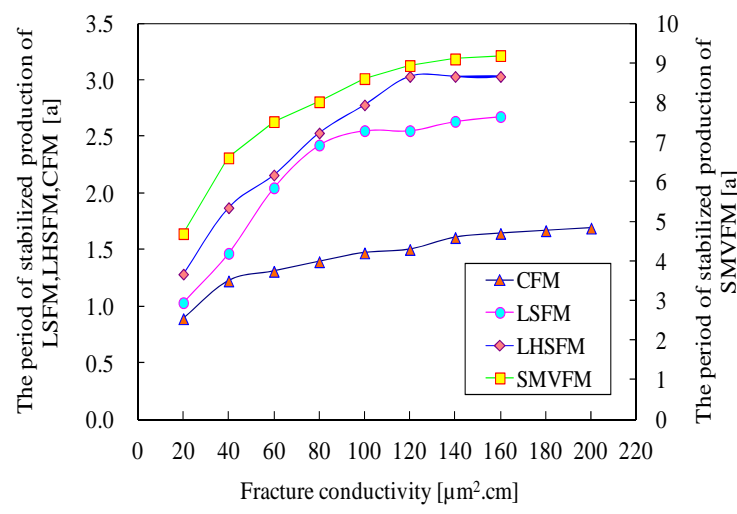

Figure 5. The relationship curve between the period of stabilized production and fracture conductivity of different fracturing mode. length range of long horizontal segment fracturing is $80 \sim 100 \mathrm{~m}$, the reasonable fracture half length range of conventional fracturing is $80 \sim 100 \mathrm{~m}$.

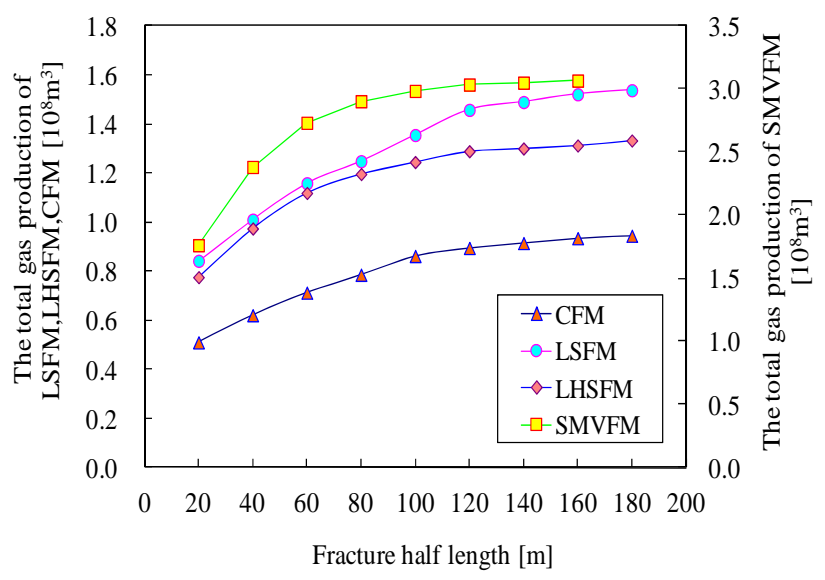

Figure 4. The relationship curve between the total gas production and fracture half length of different fracturing mode.

production and the total gas production turn obviously and flatten out. The reasons are that, although, the fracture conductivity increases, but the formation permeability is low, the limited supply capacity of gas in the formation flows into the fracture makes the deliverability of fractured horizontal well can not be further improved. Therefore, the reasonable fracture conductivity range of segment multifracture volume fracturing is $80 \sim 100 \mu \mathrm{m}^{2} . \mathrm{cm}$, the reasonable fracture conductivity range of large-scale fracturing is $80 \sim 100 \mu \mathrm{m}^{2} . \mathrm{cm}$, the reasonable fracture conductivity range of long horizontal segment fracturing is $80 \sim 100 \mu \mathrm{m}^{2}$.cm, the reasonable fracture conductivity range of conventional fracturing is $100 \sim 120 \mu \mathrm{m}^{2} . \mathrm{cm}$. The optimization results are very consistent with the reality.

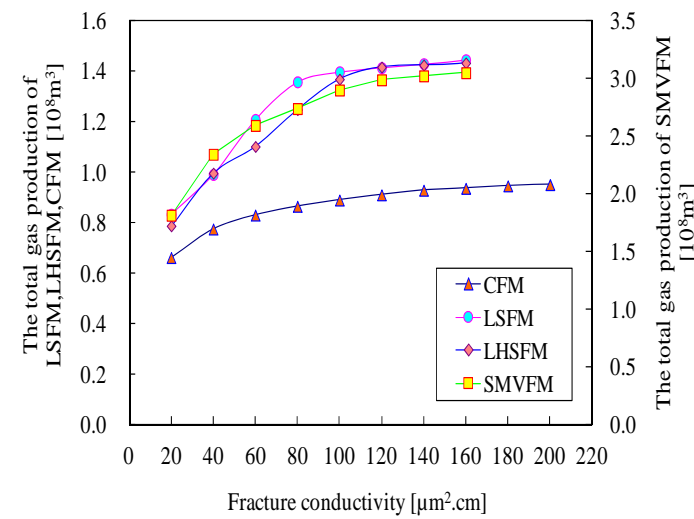

Figure 6. The relationship curve between the total gas production and fracture conductivity of different fracturing mode. 
Therefore, the optimization results are shown in table III, the results indicate that, the different reservoir conditions have suitable fracturing mode, there is a reasonable limit range of fracture parameter of different fracture mode, there is a reasonable fracturing parameter range, and there is one to one correspondence between them.

TABLE III. The configuration relationship between the reservoir conditions and fracturing parameters of horizontal well

\begin{tabular}{|c|c|c|c|c|c|c|}
\hline \multirow[b]{2}{*}{$\begin{array}{l}\text { Fracturing } \\
\text { mode }\end{array}$} & \multicolumn{3}{|c|}{ Reservoir conditions } & \multicolumn{3}{|c|}{$\begin{array}{l}\text { Reasonable fracturing } \\
\text { parameters range }\end{array}$} \\
\hline & $\begin{array}{c}\text { Gas } \\
\text { bearing } \\
\text { net pay } \\
\text { [m] }\end{array}$ & $\begin{array}{c}\text { Net pay } \\
\text { length } \\
\text { of horizontal } \\
\text { segment } \\
{[\mathrm{m}]}\end{array}$ & $\begin{array}{c}\text { Cumulative } \\
\text { interlayer } \\
\text { thickness } \\
{[\mathrm{m}]}\end{array}$ & $\begin{array}{c}\text { Fracture } \\
\text { interval } \\
\\
{[\mathrm{m}]} \\
\end{array}$ & $\begin{array}{c}\text { Fracture } \\
\text { half } \\
\text { length } \\
\text { [m] }\end{array}$ & $\begin{array}{c}\text { Fracture } \\
\text { conductivity } \\
{\left[\mu \mathrm{m}^{2} . \mathrm{cm}\right]}\end{array}$ \\
\hline SMVFM & $2 \sim 9$ & 650 900 & $0 \sim 1.5$ & 40 60 & $40 \sim 60$ & $80 \sim 100$ \\
\hline LSFM & $4 \sim 6$ & $<500$ & $0 \sim 1$ & $90 \sim 130$ & $100 \sim 120$ & $80 \sim 100$ \\
\hline LHSFM & $1 \sim 3$ & $>900$ & $0 \sim 1.5$ & $90 \sim 110$ & $80 \sim 100$ & $80 \sim 100$ \\
\hline CFM & $1 \sim 8$ & $<650$ & $0 \sim 2.5$ & $90 \sim 130$ & $80 \sim 100$ & $100 \sim 120$ \\
\hline
\end{tabular}

\section{CONCLUSIONS}

According to the different reservoir conditions, the fracturing mode of horizontal well is optimized. Based on the coupled numerical simulation model between the matrix of gas reservoir and hydraulic fracture of each typical horizontal well of different fracturing mode, the reasonable fracturing parameters of different fracture mode are optimized using the numerical simulation method. With the increase of fracturing parameters, the period of stabilized production and the total gas production increase gradually, the increasing trends become slow, and there is a reasonable fracturing parameter limit range. The different fracturing mode is suitable for reservoir conditions; the reasonable fracturing parameters are suitable for the fracturing mode.

\section{ACKNOWLEDGEMENTS}

This work was financially supported by the National Major Project "Large Oil Gas Field and CBM Development” No. 2011ZX05052, Special Fund No. 2011ZX05010-002, Key Project of Heilongjiang Education Apartment No. 12511z003 and National Natural Science Foundation No. 51074035.

\section{REFERENCES}

[1] Wang Guo-Yong, Practice and recognition of horizontal well development in tight sandstone gas reservoirs: a case study from block Su53. Journal of Oil and Gas Technology, 34(5), pp.153-157, May 2012.

[2] Wang Guo-Yong, Technical advantages and limitations of integrated development of Sulige gas field with horizontal wells: a case study with block Su53.Special Oil and Gas reservoirs, 19(1), pp.62-65, February 2012.

[3] Wu Ze-Xin, Application and effect analysis of segment multi-fracture volume fracturing technique in horizontal wells of tight sandstone gas reservoir. Science Technology and Engineering, 13(7), pp.1957-1960, March 2013.

[4] Skoreyko F, Sammon P H, Melichar H, Use of PEBI grids for complex advanced process simulators. SPE Reservoir Simulation Symposium, Houston, Texas, SPE 79685, pp.3-5, February 2003.

[5] Heinemann Z E, Brand C, Munka M, et al, Modelling reservoir geometry with irregular grids.SPE Reservoir Simulation Symposium, Houston, SPE 18412, pp.6-8, February 1989.

[6] Bae A, Flynn J, Reiso E, On near wellbore modeling and real time reservoir management. SPE 66369, 2001.

[7] Schlumberger GeoQuest, Simulation software manuals: near wellbore modeling, Abingdon: Schlumberger Information Solutions, pp.30-31, 2006. 